\title{
From 'sheep' to 'amphibian': English vocabulary teaching strategies in South African township schools
}

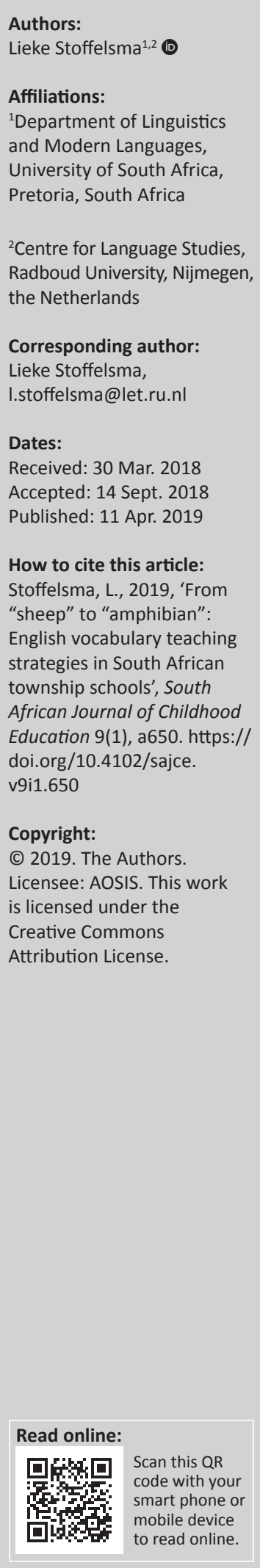

Background: South African learners have performed consistently poorly in reading assessments. This paper addresses two key components in improving reading literacy: vocabulary development and teacher knowledge and skills required for quality vocabulary instruction.

Aim: This small-scale exploratory study reports on the English vocabulary teaching strategies of eight Grade 3 teachers in South African township schools serving poor communities and their implementation of these strategies in practice.

Setting: The Western Cape teachers taught English Home Language (HL) learners. The Eastern Cape teachers taught Xhosa HL and English First Additional Language (FAL) learners.

Methods: Teacher interviews and classroom observations.

Results: The teachers used a range of basic vocabulary teaching strategies that complied with evidence-based vocabulary teaching strategies identified in the literature. However, most of the strategies employed did not reach an advanced level of active learning in which students were challenged and took ownership of their own vocabulary learning. Results showed that especially the English FAL teachers relied heavily on their L1 for vocabulary instruction.

Conclusion: Grade 3 teachers in South African schools that serve poor communities are capable of providing rich print exposure in their classrooms showing that schools can, to a certain extent, play a compensatory role for the limited literacy opportunities in homes of children from low socio-economic backgrounds. However, in order for the learners to develop a more durable, rich vocabulary their teachers would need to engage in more interactive and in-depth instruction. Implications for policy are discussed.

Keywords: vocabulary; vocabulary instruction; teaching strategies; L2 vocabulary development; South Africa; high-poverty schools.

\section{Introduction}

In 2016, a total number of 12810 South African Grade 4 learners from 293 different schools participated in the Progress in International Reading Literacy Study (PIRLS). The study was the fifth of a series of international comparative studies focusing on reading literacy of Grade 4 learners. Results showed that $78 \%$ of the South African learners, with an average age of 10.6 years, could not read for meaning or retrieve basic information from a text to answer simple questions. Reading performance in African languages was very low (Howie et al. 2017). This was not the first time that South African learners have performed poorly in reading assessments. South Africa's participation in previous cycles of PIRLS (2006 and 2011) shows consistently low reading comprehension levels. In addition to the PIRLS study results, the SACMEQ $^{1} 2007$ study showed that almost 63\% of South African Grade 6 pupils were not competent in reading (Moloi \& Chetty 2011).

To understand the literacy challenges that South Africa is facing, it is important to take into account that huge inequalities exist within the educational system. Between $81 \%$ and $83 \%$ of learners in (sub)urban schools have acquired basic reading skills in Grade 5, compared to 26\% in rural and 28\% in township schools (Spaull 2016). South Africa's inequalities in education translate into large labour market inequalities, because contributions of education to income are much stronger at higher levels of education (Van der Berg 2008). Improving the literacy skills of children from rural and township schools should be considered a priority as this has a relatively high impact on the future of many young generations.

1.The Southern and Eastern Africa Consortium for Monitoring Educational Quality (SACMEQ $)$ has published a broad range of comparative educational studies, including students' achievement in reading and mathematics in 16 countries in Southern and Eastern Africa. 
In spite of educational reforms and literacy interventions, the reading crisis in South Africa seems difficult to resolve. One of the key questions to be addressed is: What causes these low literacy levels? Spaull (2017) states that low literacy levels are rooted in the fact that many South African teachers have not acquired specialised knowledge to teach reading during their pre-service and in-service teacher training. Consequently, they are often not aware of the key reading components (phonics, vocabulary, comprehension, fluency and motivation) and how to teach these effectively. Another challenge is the lack of educational resources in the country. The Department of Basic Education (2014) estimates that only $37 \%$ of learners in primary schools in South Africa have access to a classroom or school library, which limits the learners' exposure to print and their opportunities for reading.

This article addresses one of the key components in improving reading literacy: vocabulary development and teacher knowledge and skills required for quality vocabulary instruction. Research from first language (L1) and second language (L2) settings shows that vocabulary knowledge is one of the most important prerequisites for becoming a fluent reader, as it correlates strongly with reading proficiency (Helman \& Burns 2008; Read 2004; Stæhr 2008). Reading research provides ample evidence that emphasising vocabulary learning and creating a vocabulary-rich environment are key factors in effective reading instruction (Grabe 2004).

Vocabulary development of children is influenced by their home background and school context. In general, children from low socio-economic (SE) backgrounds have a poorer understanding of words. An SE gap in vocabulary can be established as early as at the age of 18 months (Fernald, Marchman \& Weisleder 2013). Recent research in the South African context shows that initial vocabulary knowledge at the beginning of Grade 3 is a strong predictor of vocabulary development during the school year and that children who start school with weak language skills tend to stay weak (Pretorius \& Stoffelsma 2017). Moreover, research shows that it is difficult to change children's vocabulary development once it is established in early childhood years, unless intervention occurs (Hart \& Risley 1995).

\section{First language versus second language vocabulary}

In general, L2 readers face particular reading challenges that L1 readers do not face. For example, L2 language learners lag behind their first language peers in reading literacy skills (Droop \& Verhoeven 2003; Mullis et al. 2007), reading comprehension, reading speed (Alderson 1984) and development of vocabulary skills (Anderson 1999). L2 readers generally have a different starting point with regard to linguistic knowledge (i.e. lexical, grammatical and discourse knowledge) than L1 readers. Grabe (2009) argues that children who start to read in their L1 by the age of 6 will already have developed implicit knowledge of syntax, morphology and phonology. Furthermore, they are likely to know between 3000 and 8000 words orally before they start to read. It will take L2 learners at least several years to develop such knowledge and abilities (Grabe 2009). In addition, it is generally assumed that L2 readers have far less exposure to reading materials in the $\mathrm{L} 2$ than their $\mathrm{L} 1$ counterparts, because L2 readers only encounter L2 words in their school setting, whereas L1 readers are likely to come across more L1 words in their daily routines (e.g. books, newspapers, magazines, public information boards, and so on) (Grabe 2009).

Because of the language dynamics in South Africa, currently more than $70 \%$ of the Grades $1-3$ learners learn to read in an African language and then switch to English in Grade 4. The South African Curriculum and Assessment Policy Statement (CAPS) (Department of Basic Education 2011) stipulates that Grade 3 learners learn to read primarily in their home language (HL), while reading and writing in English as First Additional Language (FAL) is set for only 4 hours per week (Department of Basic Education 2011). Research shows that English FAL learners are not adequately prepared for Grade 4. Already in the 1990s, the Threshold Project revealed that South African learners were having difficulties in making the transition from the first language to English as the medium of instruction (MacDonald \& Burroughs 1991). More recent local studies have suggested that young South African English FAL learners are struggling with vocabulary (Sibanda 2014), while Wilsenach (2015) found low vocabulary levels amongst both African L1 and English FAL learners. A recent study (Pretorius \& Stoffelsma 2017) confirms existing differences between L1 and L2 Grade 3 learners in vocabulary development. It shows that the English HL learners know almost double the number of words than their FAL peers. The English FAL learners on average knew only $27 \%$ of the most frequently used words at the end of their Grade 3 year (Pretorius \& Stoffelsma 2017). The good news is that learners from township schools in both the Eastern and Western Cape were found to be capable of increasing their active word knowledge through the academic year by about $9 \%$, which equals a medium-to-high learner effect (Pretorius \& Stoffelsma 2017). The next question is how to maximise the vocabulary learning effects amongst these learners.

In addition to the unpreparedness of English FAL learners for the transition to English as the Language of Teaching and Learning (LoTL) in Grade 4, the contextual environment is not sufficiently resourced to support vocabulary development. The percentage of learners who have their own reading textbook in schools serving poor communities is low: from $35.6 \%$ in Quintile 1 schools to $43.4 \%$ in Quintile 3 schools (Spaull 2011). A recent study on the use of graded readers in township school classrooms showed that the availability of readers is limited and that teachers do not adhere to the reading schemes (Stoffelsma 2019).

\section{Teaching vocabulary at early primary level}

The majority of our vocabulary growth occurs through incidental exposure to oral or written language (Cunningham 2005). However, intentional instruction of vocabulary within the language curriculum should be given emphasis in any 
curriculum because the effectiveness of direct vocabulary instruction is supported by research evidence (Nation 2001; Read 2004). Obviously, it is impossible to teach children all the words they need to know, and many words are learned incidentally through reading and print exposure. Consequently, explicit instruction might not yield a large vocabulary development; it does, however, offer possibilities to teach keywords for comprehension or words that are not likely to be learned in contextual word-learning (Grabe 2009). Stahl (2005) emphasises that for vocabulary instruction to be effective, repetition and multiple exposures to words are important. Students need to engage in deep word processing, and have sufficient opportunities to encounter words repeatedly and in a variety of contexts, both in written and oral language. Direct teaching should alternate with teaching strategies for wordlearning. Raising learners' word awareness and teaching them to notice when they do not understand a word will help them increase their proficiency on their own. Teaching students to master strategies that they can use on their own, without the help of a teacher, will be more sustainable strategy in the long term (Blachowicz \& Fisher 2015).

The CAPS 2011 English FAL and HL emphasise the use of basic vocabulary teaching strategies, such as teaching high-frequency words, using word walls, extensive print exposure, using personal dictionaries, stimulating independent reading, playing word games and teaching how to discover word meaning. Vocabulary targets are set for each grade and for English FAL learners, a list of 300 high-frequency words in English is provided. However, CAPS acknowledges that this list is not fully reflective of South African learners' vocabulary needs as it is based on vocabulary research from the UK (Sibanda 2014).

Suggestions in the literature for direct vocabulary instruction are numerous, and often the ideas and approaches have overlapping constructs. Selection of the appropriate vocabulary instruction techniques depends on the quality of the teacher, the available resources and target audience. For the current study, the vocabulary instruction frameworks by Blachowicz and Fisher (2015) and Lems, Miller and Soro (2017) were identified as relevant, because of their emphasis on second language learners and their evidence-based approach. Blachowicz and Fisher (2015) present four research-based guidelines for vocabulary instruction and related vocabulary strategies that can be integrated into school curricula. Their work is based on the Multifaceted, Comprehensive Vocabulary Instruction Program (MCVIP) model by Baumann et al. (2012). The four guidelines for good vocabulary instruction in this model include:

- provide rich and varied language experiences (Table 1, point 1)

- teach individual words (Table 1, point 2)

- teach word-learning strategies (Table 1, point 3)

- foster word consciousness. (Table 1, point 4)

In addition to these four guidelines, the nine learning strategies proposed by Lems et al. (2017) were deemed appropriate for the current study because of their focus on English L2 learners. They propose nine effective word-learning strategies based on the work of numerous scholars (cf. Ellis \& Beaton 1993; Hoyt 2002; Nation 2001). They stress the importance of making students active vocabulary learners by teaching them strategies that they can use independently. Table 1 presents the nine strategies as proposed by Lems et al. (2017) in relation to the four guidelines proposed by Blachowicz and Fisher (2015).

\section{Provide rich and varied language experiences}

Within this guideline, Blachowicz and Fisher (2015) (Table 1) propose four strategies that enhance rich and varied language experiences in classrooms. Firstly, classrooms should be flooded with words and print to enhance incidental wordlearning of the learners. This is based on the idea that a printrich environment enhances opportunities for interesting and meaningful word encounters, which, in turn, can enhance incidental vocabulary learning (Cunningham 2005). Secondly, fast instruction can be used to explain vocabulary of which the concept is familiar but the word is not and which is building on knowledge that students already have. Thirdly, they propose focused instruction for words where the teaching of a new concept is required, using deeper levels of processing and semantically rich teaching. At this level of instruction, definitions and contextual information are provided, as well as multiple exposures to cater for deep levels of processing. Finally, they argue that a rich and varied language experience should include reading in the classroom,

TABLE 1: Vocabulary teaching strategies based on Blachowicz and Fisher (2015) and Lems et al. (2017).

\begin{tabular}{|c|c|c|}
\hline Variable & $\begin{array}{l}\text { Strategies of good vocabulary instruction by Blachowicz } \\
\text { and Fisher (2015) }\end{array}$ & Effective word-learning strategies (Lems et al. 2017) \\
\hline $\begin{array}{l}\text { 1. Provide rich and varied language } \\
\text { experiences }\end{array}$ & $\begin{array}{l}\text { - Flooding classroom with print } \\
\text { - Fast instruction or simple word lesson } \\
\text { - Focused instruction } \\
\text { - Wide reading }\end{array}$ & $\begin{array}{l}\text { - Use word cards or flash cards } \\
\text { - Word walls in classroom } \\
\text { Provide enough repetitions of words through print exposure }\end{array}$ \\
\hline $\begin{array}{l}\text { 2. Teach individual words (high-frequency } \\
\text { and domain-focused) through explicit } \\
\text { instruction }\end{array}$ & $\begin{array}{l}\text { - Fast instruction or simple word lesson } \\
\text { - Mocused instruction } \\
\text { through choice, discussion and working with words } \\
\text { (semantic maps, graphic organisers, word webs, and so on) } \\
\text { - Use word definitions }\end{array}$ & $\begin{array}{l}\text { - Use L1 as a resource to explain new words } \\
\text { - Pre-teach vocabulary before reading a new text } \\
\text { - Use pictures or let students draw, say, write or physically } \\
\text { demonstrate new words } \\
\text { - Form a mental image connected to the meaning of a new word } \\
\text { (keyword method) }\end{array}$ \\
\hline $\begin{array}{l}\text { 3. Develop students' independent } \\
\text { word-learning strategies }\end{array}$ & $\begin{array}{l}\text { - Students' self-control of learning } \\
\text { - Morphemic analysis } \\
\text { - Contextual analysis } \\
\text { - Dictionary use }\end{array}$ & $\begin{array}{l}\text { - Teach different word forms (e.g. sleep, sleeping, sleepless, } \\
\text { sleepy, and so on) } \\
\text { - Make daily use of dictionaries }\end{array}$ \\
\hline 4. Foster word consciousness & - Using word games and wordplay & - \\
\hline
\end{tabular}

Source: Based on Blachowicz, C.L.Z. \& Fisher, P.J., (eds.), 2015, Best practices in vocabulary instruction, Guilford Press, New York and Lems, K., Miller, L.D. \& Soro, T.M., 2017, Building literacy with English language learners, insights from linguistics, 2nd edn., The Guilford Press, New York. 
especially read-alouds and discussion about the stories that are being read. Research shows that reading for enjoyment exposes learners to a rich vocabulary and words that they are unlikely to encounter in speech; therefore, written language is a more effective way of building a child's vocabulary than oral language (Cunningham 2005; Mol \& Bus 2011).

In addition to these strategies, the following teaching strategies proposed by Lems et al. (2017) were added to guideline 1: use word cards or flash cards, use word walls in the classroom and provide enough repetitions of words through print exposure.

\section{Teach individual words}

The focus here is on both teaching high-frequency words, as well as domain-focused vocabulary. L2 readers will profit from learning high-frequency words (Nation 2001; Read 2004). Blachowicz and Fisher (2015) (Table 1) distinguish between teaching simple individual word lessons, which are similar to the fast instruction strategy previously described, and more mature word-learning strategies. The latter include students' involvement in actively constructing word meaning. Just as with the focused strategy instruction previously described under guideline 1, mature-word-learning includes definitional information, contextual information and usage examples, but it goes a step further by emphasising active processing of words through choice, discussion and working with words. Examples of techniques to actively engage students with words include constructing semantic maps, using graphic organisers, comparing and contrasting, and using word webs or clusters that represent semantic relatedness of words. Research shows that instruction that goes beyond teaching definitions and includes active word processing activities leads to higher vocabulary learning (Blachowicz \& Fisher 2000). If we look at the nine strategies proposed by Lems et al. (2017), four are related to explicit vocabulary instruction and suitable to be integrated in guideline 2. These are the following: use L1 as a resource to explain new words; pre-teach vocabulary before reading a new text; use pictures or let students draw, say, write or physically demonstrate new words and form a mental image connected to the meaning of a new word (keyword method).

\section{Teach word-learning strategies}

This guideline refers to teaching students the appropriate skills needed to learn words on their own (Table 1). The first pillar of this guideline is that students should be allowed to select words on their own. Evidence on self-selection of vocabulary shows that students who choose their own words to learn, learn faster and retain meaning longer than if a teacher selects new words for them (Ruddell \& Shearer 2002). Secondly, teachers should provide instruction to their learners in three types of word-learning strategies: the development of morphemic awareness, contextual analysis and the use of dictionaries. The importance of morphemic awareness for vocabulary learning is advocated by many scholars. Research shows that $60 \%$ of the words that children encounter during reading in English after fourth grade are morphologically complex (Egan \& Pring 2004). At increasing grade levels, the knowledge to engage in morphological decomposition and how to use contextual clues from text becomes more important (Tighe \& Binder 2015). Moreover, research shows that teaching students about awareness of prefixes, suffixes and word-roots enhances their ability to infer the meaning of words (Baumann et al. 2002). The second word-learning strategy, contextual analysis, teaches students to use the context in which a word occurs to derive its meaning. A meta-analysis by Kuhn and Stahl (1998) on teaching context-use instruction found a positive effect of teaching students to use context, although providing children with the opportunities to practice guessing from context was almost as effective as teaching learners inferencing techniques. The use of dictionaries will enhance students' self-selection of words and independently develop their vocabulary. Two word-learning strategies proposed by Lems at al. (2017) partly overlap with guideline 3 of the model: teaching of different word forms and making daily use of dictionaries.

\section{Foster word consciousness}

While in the original MCVIP model, the emphasis within this guideline was on word categories, word relationships and wordplay, Blachowicz and Fisher (2015) (Table 1) have moved the focus more towards an affective or motivational approach. As in the original model, they do argue that students learn by playing with words, but they also argue that teachers should be good and enthusiastic models of word-learning. They stress that both practices will enhance a positive environment of word-learning. Lems et al. (2017) did not include any strategies on fostering word consciousness.

Based on the presented evidence-based framework of effective vocabulary instruction, the study's main aim was to investigate the vocabulary teaching strategies used by Grade 3 teachers in schools that serve disadvantaged communities. The research was led by the following two research questions:

- What kind of vocabulary teaching strategies do Grade 3 teachers use in their classrooms?

- What kind of vocabulary teaching strategies do Grade 3 teachers use in practice?

\section{Research methods and design Schooling context}

Teachers from four different low SE urban primary schools participated in the study: two schools in the Eastern Cape and two in the Western Cape. All schools served disadvantaged communities. The schools in the Western Cape were English HL primary schools, with Afrikaans as their FAL. The schools served mainly low-income mixed race communities and were situated in the township areas of Cape Town. The two schools in the Eastern Cape, situated in the township areas of Port Elizabeth, had Xhosa HL as their Language of Teaching and Learning (LoTL) and English as their FAL in Foundation Phase. All four schools participated in a 3-year literacy project, the Zenex Literacy Project (2015-2017). The aim of the Zenex project was to 
improve learner literacy levels of Foundation Phase learners through improved classroom literacy practices at quintiles 1-3 schools across three provinces. Vocabulary did receive some attention in the project at teacher workshops. However, this article is not intended as an evaluation of this aspect of the project - but more as an illustration of how a small sample of teachers dealt with vocabulary in their daily classroom practices.

\section{Participants}

Convenience sampling was applied in the selection of the teachers. Eight female Grade 3 teachers volunteered to participate in the study, two from each school. All teachers were observed while teaching and seven teachers were interviewed: three from the Eastern Cape and four from the Western Cape. One teacher was unavailable to be interviewed because of illness.

\section{Test instruments}

Based on the vocabulary teaching strategies by Blachowicz and Fisher (2015) and Lems et al. (2017), the vocabulary instruction framework (Table 1) was used to identify reported and observed vocabulary teaching strategies.

A semi-structured interview approach (Bryman 2004) was used based on an interview guide with six questions (see Box 1). The first two questions addressed vocabulary learning and the use of teaching strategies in the classroom. To provide a clearer picture of the teaching context, questions 3 and 4 addressed the vocabulary sources available at school and at home. To get a better understanding of the teachers' estimation of the vocabulary level of their students, questions 5 and 6 targeted learners' vocabulary levels.

BOX 1: Interview guide.

1. In what way do you as a teacher stimulate vocabulary learning in your
classroom with your learners?
2. What vocabulary teaching strategies do you use?
3. What is the major source of the words that you teach in class?
4. What are the sources for the children to get their new vocabulary from?
5. Do the learners sometimes surprise you with new words?
6. Are your learners ready for the level of English that they will encounter in
Grade 4 ?

Note: Video recordings were used to observe classes in eight different classrooms, amounting to a total of 6 hours and 23 mininutes of video recordings (see Table 2). Teachers were informed that the observations were part of the literacy project, they were asked to teach as they would normally do.

TABLE 2: Overview of teacher sample.

\begin{tabular}{lccc}
\hline Variable & English & Classroom observation & Children in class \\
\hline Teacher A & HL & 27 min $51 \mathrm{~s}$ & 38 \\
Teacher B & HL & 47 min 09 s & 35 \\
Teacher C & HL & $56 \min 53 \mathrm{~s}$ & 41 \\
Teacher D & HL & $67 \operatorname{min~08~s}$ & 40 \\
Teacher E & FAL & $51 \operatorname{min~33~s}$ & 46 \\
Teacher F & FAL & $37 \operatorname{min~03~s}$ & 35 \\
Teacher G & FAL & $39 \operatorname{min~23~s}$ & 43 \\
Teacher H & FAL & $56 \operatorname{min~32~s}$ & 40 \\
\hline Total & - & $6 \mathbf{h ~ 2 3 ~} \min 32 \mathrm{~s}$ & - \\
\hline
\end{tabular}

HL, Home Language; FAL, First Additional Language; min, minutes; s, seconds.
Participation was voluntary and unpaid. All teachers gave permission for the recording of the interviews.

\section{Data collection procedures}

The interviews were administered during school hours. The lessons were recorded during regular class hours. For the Eastern Cape schools, only FAL lessons were recorded.

\section{Data analysis}

Interviews were recorded, transcribed and analysed. For questions $1-3$, the reported vocabulary teaching strategies were categorised following the vocabulary instruction framework (see Table 1). For example, the answer 'I try to bring books or articles (to the classroom) that are related to the themes' was labelled as category 1 (print-rich environment). The answer 'I just give them the definitions and then they have to revise' was labelled as category 2 (use of word definitions). And the answer 'I've put the word there and then explain it in Xhosa, so that they can understand' was categorised as 2 (use L1 as a resource to explain new words). The analysis amounted to a total number of 69 reported strategies.

Questions 3-6 were analysed separately. For each question, the responses were categorised into occurring themes. The language of the interviewees is an important feature of descriptive analysis (Ritchie \& Lewis 2012). Quotes are therefore integrated into the reporting as transcriptions of colloquial speech, which may contain grammatical inaccuracies. Quotes are reported in italics and for each quote the source is reported.

All video recordings were transcribed verbatim. The vocabulary instruction framework (see Table 1) was used to investigate the vocabulary teaching strategies that were captured both on video and in the transcripts. The same approach as used with the interviews was applied: observed vocabulary teaching strategies were categorised according to the vocabulary instruction framework.

\section{Ethical considerations}

Permission to work in these schools was obtained at national and provincial levels by the project. Within the framework of the larger project, a separate vocabulary study was conducted, for which two schools from each province were asked to volunteer to participate. The vocabulary research included a study on vocabulary trajectories of Grade 3 learners (Pretorius \& Stoffelsma 2017), a study on print exposure in Grade 3 classrooms (Stoffelsma 2019) and the current study.

\section{Results \\ Provide rich and varied language experiences}

The outcomes of the interviews and classroom observations regarding the first guideline are reported in Table 3. 
TABLE 3: Teachers' reported and observed strategies relating to rich and varied language experiences. Strategies used

\begin{tabular}{cccccccccc}
\multicolumn{4}{c}{ Western Cape } & & \multicolumn{4}{c}{ Eastern Cape } \\
\cline { 1 - 3 } \cline { 5 - 8 } & B & C & D & & E & F & G & H
\end{tabular}

(A) Flood classroom with words or print-rich environment

(1) Use word cards or flash cards

(2) Word walls in classroom

(3) Use of vocabulary notebooks

(4) Bring in additional storybooks, articles and magazines

(B) Fast vocabulary instruction or simple word lesson ${ }^{2}$

(1) Make sure students see the word and can pronounce it

(2) Provide a synonym

(3) Explain words by presenting oral and written context (provide a sentence or give or ask for example)

(4) Ask for semantic response (students give sentence)

(5) Ask students for connection or synonym, discuss nuances

(6) Ask simple word comprehension questions (What is..?)

(C) Wide reading and discussion about the reading

(1) Encourage (independent) reading in class

(2) Extracting words from textbooks and storybooks

(3) Use (storybooks from) the reading corner

(4) Library visits (outside school)

$\begin{array}{cccccccc}- & \mathrm{x} & \mathrm{x} & \bullet & \bullet & - & - & \bullet \\ \mathrm{x} & \mathrm{x} \bullet & \mathrm{x} \bullet & \mathrm{x} \bullet & \mathrm{x} \bullet & \mathrm{xx} & \mathrm{x} \bullet & \bullet \\ \mathrm{x} & \mathrm{x} & - & \mathrm{x} & - & - & - & - \\ - & \mathrm{x} & \bullet & \bullet & \bullet & - & - & -\end{array}$

$\mathrm{x}$, reported during interviews; $\bullet$, observed during classroom observations.

Table 3 shows that all teachers reported and demonstrated that they used word walls in their classrooms. Only three reported using vocabulary notebooks for students to write down new words. Half of the teachers added additional reading material to the existing prescribed textbooks in the form of poems, short stories, magazines or articles.

The fast vocabulary instruction strategy was fully applied by the English HL teachers and partly by the English FAL teachers. The more elaborate teaching tasks (providing synonyms, asking for semantic responses and asking for connection or discussing nuances) in which students are more actively engaged in word processing were not observed in the English FAL classes. Word explanations during fast vocabulary instruction were highly diverse, ranging from more simple explanations - such as 'Where are the feet? Show me your feet' (Teacher E, Grade 3, English FAL, female); 'Yintoni i sheep? What is a sheep? Where do we find sheep?' (Teacher H, Grade 3, English FAL, female) - to more difficult ones - such as 'What is an example of an amphibian? And are they warm blooded, or cold blooded?' (Teacher B, Grade 3, English HL, female).

All teachers taught their learners new words and concepts that they extracted during the reading of textbooks or storybooks, and asked them simple comprehension questions. Again, the range of words was quite diverse, examples include: 'What is a pictograph?' (Teacher A, Grade 3, English HL, female); 'What is a wound?' (Teacher D, Grade 3, English HL, female); 'What do I mean when I say duties?' (Teacher F, Grade 3, English FAL, female); 'What is a church?' (Teacher $\mathrm{H}$, Grade 3, English FAL, female); 'What is to float?' (Teacher G, Grade 3, English FAL, female). The answers to the questions, sometimes provided by the teachers themselves, did not always give a full clarification of the word or concept, as the following examples illustrate:

2.In their model, Blachowicz and Fisher (2015) present the strategy of 'Fast instruction" under strategy (1) and 'Simple word lesson' under strategy (2). Because of their under strategy (1) and 'Simple word lesson' under strategy (2). Because of their
similar characteristiques, they are merged and presented here as one strategy under component (1).
Teacher: 'What is to help?' (Teacher E, Grade 3, English FAL, female)

Learner: 'Ukunceda (to help)' (Learner A, Grade 3, female)

Teacher: 'Yes. You come to your mother, when your mother and father are doing something else, you have to help with something else.'

Teacher: 'Right, what is a pictograph? What did I say, Azza what is a pictograph?' (Teacher A, Grade 3, English HL, female)

Learner: 'It's a sort block where there is pictures in.' (Learner B, Grade 3, female)

Teacher: 'Alright, and what is a bar graph? What is the difference Liam?' (Teacher A)

Learner: 'There's bars in it.' (Learner C, Grade 3, male)

Teacher: 'There's bars and what do we do?' (Teacher A)

Learner: 'You use the bars to count.' (Learner C, Grade 3, male)

Teacher: 'You use the bars to count. And how does the pictures help you in the pictograph?' ' (Teacher A)

Whole class in chorus: 'To count.

\section{Teach individual words}

During the interviews with the English FAL teachers, one vocabulary teaching strategy came up that was not part of the framework: using phonics to teach new words, as explained by Teacher E:

'I start with the phonics for the week. Then you build words from those phonics, then we spell and segment for spelling, so that then from there they build their own words (...). That's how we make vocabulary.' (Teacher E, Grade 3, English FAL, female)

During classroom observations, the following example of the 'phonics approach' was observed:

Teacher: 'Alright, masifunde amanye amagama ano A. [Alright, let's learn words that have the letter A.] Aaa.' (Teacher G, Grade 3, English FAL, female)

Learner: 'Bag'. (Learner D, male, Grade 3)

Teacher: 'Very good.' 
Only the Eastern Cape teachers reported using phonics and the L1 as a resource to explain new words. Numerous instances of code switching from English to isiXhosa were observed during the Eastern Cape classroom observations. Within the observed English FAL classes, Teacher E switched from English to isiXhosa on 45 occasions, Teacher F switched 35 times, Teacher $G$ switched 44 times and Teacher H 34 times.

Table 4 shows that the use of more time-consuming and complex strategies necessary for focused instruction (e.g. deep, semantically rich teaching of a new concept, providing definitions, planning vocabulary) was generally less popular amongst the teachers. Similarly, the more complex matureword-learning strategies were not applied, with the exception of two teachers, who demonstrated using mental images to their learners. Classroom observations showed that two of the eight teachers engaged in deep, semantically rich teaching of new concepts. Teacher B explored several concepts related to insects (e.g. 'compound eyes', 'abdomen', 'jointed legs') and Teacher D explored various concepts that surfaced during the reading of a poem (e.g. 'winding', 'weary', 'parlour'). Almost all teachers were observed using visuals and some form of written application of new words, ranging from producing simple sentences with new words, to having learners write a paragraph about a new concept.

\section{Teach word-learning strategies}

Only the Western Cape teachers used some of the independent word-learning strategies (see Table 5). Three teachers reported stimulating students to bring new words into their classrooms, two reported teaching their learners about context-use and one teacher reported using dictionaries on a daily basis. Only two teachers were observed using independent word-learning strategies in practice.

\section{Foster word consciousness}

The use of word activities and games were reported both in the Western and Eastern Cape classrooms (see Table 6). Examples included word games, students as news reporters with a microphone, spelling bees and word guessing games.

\section{Interview outcomes questions 3-6}

In addition to the vocabulary teaching strategies reported above, the interviewed teachers were asked some questions related to sources of vocabulary (see Box 1). In response to question 3 ('What is the major source of the words that you teach in class?'), teachers reported using the themes from the prescribed textbooks for English, life skills, and mathematics, readers and storybooks, dictionaries, words that students bring to class and one teacher mentioned Google. When they were asked about the vocabulary sources for their learners (question 4), all teachers reported that their learners acquire new vocabulary through watching television at home, one said they acquire new words from interaction with their parents and three teachers assumed that their learners would learn new words from reading books. Other vocabulary sources that were reported included: reading magazines, storytelling at home and two teachers from the Western Cape reported that children use the Internet:

'Yes, you will be surprised actually, because the parents have the phones, so they will go onto the Internet and they will maybe find out things on the Internet.' (Teacher D, Grade 3, English HL, female)

TABLE 5: Teachers' reported and observed strategies relating to teaching independent word-learning.

\begin{tabular}{|c|c|c|c|c|c|c|c|c|}
\hline \multirow[t]{2}{*}{ Strategies used } & \multicolumn{4}{|c|}{ Western Cape } & \multicolumn{4}{|c|}{ Eastern Cape } \\
\hline & A & B & C & D & E & $\mathbf{F}$ & G & $\mathbf{H}$ \\
\hline (1) Self-selection of vocabulary & $x$ & $x^{\bullet}$ & - & $\mathrm{x}$ & - & - & - & - \\
\hline (2) Context-use instruction & $x$ & - & - & $x^{\bullet}$ & - & - & - & - \\
\hline (3) The use of morphology & - & - & - & - & - & - & - & - \\
\hline (4) Different word forms & - & - & - & - & - & - & - & - \\
\hline (5) Use of dictionary & - & - & $x$ & - & - & - & - & - \\
\hline (6) Daily use of a dictionary & $\mathrm{x}$ & - & - & - & - & - & - & - \\
\hline
\end{tabular}

$\mathrm{x}$, Reported during interviews; $\bullet$, observed during classroom observations.

TABLE 6: Teachers' reported and observed strategies relating to fostering word consciousness.

\begin{tabular}{|c|c|c|c|c|c|c|c|c|}
\hline \multirow[t]{2}{*}{ Strategies used } & \multicolumn{4}{|c|}{ Western Cape } & \multicolumn{4}{|c|}{ Eastern Cape } \\
\hline & A & B & C & D & E & $\mathbf{F}$ & G & H \\
\hline $\begin{array}{l}\text { (1) Create a positive environment for word- } \\
\text { learning through the use of word activities } \\
\text { or games }\end{array}$ & - & $x^{\bullet}$ & - & $x x$ & $\mathrm{x}$ & $x x x$ & - & - \\
\hline
\end{tabular}

$\mathrm{x}$, Reported during interviews; $\bullet$, observed during classroom observations.

TABLE 4: Teachers' reported and observed strategies relating to teaching individual words. Strategies used

\begin{tabular}{ccccccccc}
\multicolumn{4}{c}{ Western Cape } & & \multicolumn{4}{c}{ Eastern Cape } \\
A & B & C & D & & E & F & G & H
\end{tabular}

\section{(A) Focused instruction}

(1) Deep, semantically rich teaching of a new concept

(2) Provide a definition of the term

(3) Planning vocabulary learning

(4) Written application of new words (creative writing, writing comprehension, spelling and making sentences)

(5) Visual application of new words (use pictures)

(6) Use L1 as a resource to explain new words

(7) Pre-teach words before reading a new text

(8) Phonics approach

(B) Mature word-learning strategies

(1) Semantic maps, graphic organisers, word webs, and so on

(2) Form a mental image connected to the meaning of a new word

$\begin{array}{cccccccc}- & \bullet & - & \bullet & - & - & - & - \\ - & \mathrm{xx} & \bullet & - & - & - & - & - \\ \mathrm{x} & \mathrm{x} & \bullet & \bullet & - & \bullet & - & - \\ - & \bullet & \bullet & \mathrm{x} \bullet & \mathrm{x} & \mathrm{x} & \mathrm{x} & - \\ - & \mathrm{x} \bullet & \bullet & - & \bullet & \mathrm{x} \bullet & \bullet & \bullet \\ - & - & - & - & \bullet & \mathrm{x} \bullet & \bullet & \bullet \\ \mathrm{x} & \mathrm{xx} & \bullet & - & - & \mathrm{x} \bullet & - & - \\ - & - & - & - & \mathrm{x} \bullet & - & \bullet & \bullet\end{array}$

$\mathrm{x}$, Reported during interviews; $\bullet$, observed during classroom observations. 
'They get a lot of vocabulary from watching television, and the way their parents speak to each other and to them. They obviously model the way their parents speak, so they definitely pick up vocabulary from their parents, from what they watch. Not so much books, because it doesn't seem that most have books at home, and I know this because so many of them ask me to take books home from the reading corner.' (Teacher B, Grade 3, English HL, female)

Four teachers reported that a few children belong to a library outside the school. One teacher reported that she has never taken her class to a public library for safety reasons:

The crime in this area it's bad, they don't even want to play outside because of all the shootings and gangsters that is happening outside. So the library is in the area that is scary to go to. They can't go alone because their parents they have to work. They are not exposed to the library as much as what they can be. ... For us to walk from to school to the library it would be risky, and I am responsible for them. (Teacher B, Grade 3, English HL, female)

This safety issue does not hold true for all schools; teachers from two different schools reported encouraging visits to the library and even taking the children there.

All the teachers reported that their learners sometimes surprise them with new words (question 5). They bring new words into the classroom that they have heard at home (1), on television (3) or from visits to the library (3).

'They do, they, they definitely do. They would come with new words not knowing what it means, and then I would have to explain it to them and if I don't explain to them I would show that I don't know and I would model that I would now I need to go and find the meaning in the dictionary. Sometimes I prefer not knowing because they tend to forget sometimes that you need to go find the meaning in the dictionary.' (Teacher B, Grade 3, English HL, female)

Teachers from both the Eastern and Western Cape were of the opinion that the majority of their learners will be ready for the level of English that they will encounter in Grade 4 (question 6).

\section{Discussion}

The aim of this study was to explore the vocabulary teaching strategies of Grade 3 teachers in schools serving poor communities in both the Eastern and Western Cape provinces in South Africa. Although the teachers who participated in this study were part of an intervention aimed at improving reading levels in the schools, it was not the intention to evaluate the results of that particular training. It should be taken into account, however, that these teachers are likely to be better trained in vocabulary strategies than their peers in other schools, who were not part of the literacy project. Nevertheless, even if we would assume that they are advanced vocabulary teachers, a number of interesting findings can be reported.

Firstly, the teachers employed a wide range of vocabulary teaching strategies in their Grade 3 classrooms that fit within the framework of evidence-based strategies as proposed by Blachowicz and Fisher (2015) and Lems et al. (2017). Moreover, all were capable of providing rich print exposure to the learners in their classrooms, through word walls, flash cards, reading activities and fast vocabulary instruction. This is an important finding because schools play an important role in compensating for the limited literacy opportunities in homes of children from low SE backgrounds (Howie \& Van Staden 2012). However, teachers' strategy use seemed rather limited when it came to the more advanced vocabulary instruction strategies, such as focused instruction or matureword strategies. Blachowicz and Fisher (2015) argue that the focused instruction 'is the type of conceptual instruction that takes time and energy, but it pays off with deep learning of those less familiar words, often ones that are less concrete' (p. 200). The data from this study seem to suggest that teachers were not actively engaging students in their vocabulary development at a cognitively challenging level; most, not all, resorted to rote learning and word drilling. Stahl (2005) cautions against simply word repetition or word drill, and argues that vocabulary instruction should provide students with opportunities to encounter words repeatedly and in a variety of contexts.

The study also showed that teachers' strategies to teach learners independent word-learning were limited to nonexistent. These types of strategies require explicit instruction, good planning, practice and feedback and scaffolding that leads to more student responsibility and a metacognitive focus (Blachowicz \& Fisher 2015). In order for learners' vocabulary development to be successful and sustainable, they need to understand how to derive the meaning of words from the context in which they occur and be trained in taking control of their own learning.

Another important finding was that there was no mention of high-frequency words by the teachers, nor was there teaching of high-frequency words observed in the classrooms. Targeting the high-frequency words did not seem to be a learning goal on its own. Although the different frequency levels of words were explained in the Zenex project workshops, this information does not seem to have been taken up by the teachers in their daily practices. This is rather surprising; besides the emphasis on frequency levels in the project workshops, vocabulary targets are set for each grade and for English FAL learners, a list of high-frequency words in English is provided in CAPS. As noted above, however, CAPS (2011) acknowledges that this list is not reflective of South African learners' vocabulary needs (Sibanda 2014).

A significant observation was the amount of code switching in the Eastern Cape classrooms and the use of L1 to explain new words. Schmitt (2008) argues that there is sufficient research evidence that supports using the L1 in teaching L2 learners of English to facilitate the form-meaning linkage. This helps in providing an easy access to the meaning of a word that is already in the memory. However, after this initial stage, it becomes important for the learner to encounter the new lexical item in L2 contexts so that contextual word 
knowledge can develop. Given the different stages that exist in vocabulary learning processes, Schmitt (2008) calls for using different teaching methods at different stages of vocabulary learning. The data in our study suggest that the Eastern Cape teachers were still teaching at the initial level of form-meaning linkage, by explaining words such as 'sheep', 'church', 'hip', 'feet', and so on, in isiXhosa and by allowing learners to answer in their mother tongue. The question is whether Grade 3 learners should not also be exposed to other strategies besides this basic-level strategy of vocabulary learning, and whether they would not benefit from more in-depth semantic processing by encountering words in an L2 context, rather than in their L1.

Finally, a point of methodological importance is that not all the vocabulary strategies that teachers used in practice were reported during the interviews. The study showed that the classroom observations allowed for a more complete picture of the teaching strategies used, indicating that data triangulation is important in this type of investigation.

\section{Limitations of the study}

The results of this study need to be interpreted in light of a few limitations. Firstly, there were no control schools involved in the study, which made it difficult to determine whether the observed teacher strategies would also occur in schools that are not involved in interventions such as the Zenex project. Secondly, the sample size of this exploratory study was relatively small, which makes the generalisability of the results limited. It should therefore be considered as an illustration of how a small sample of teachers dealt with vocabulary in their daily classroom practices. A final limitation is that, as in all educational research, the data consisted of instantaneous classroom observations transferred into a laboratory setting, and should be interpreted as such. Whether the findings of the current study are representative of the teaching practices in South African schools at national level should be investigated in future research on a larger scale. Further research on how vocabulary is taught and developed in Foundation Phase classrooms - in both L1 and FAL - is urgently called for.

\section{Conclusion}

The transition from Grade 3 to Grade 4 is an important one: the focus on the reading demands of learners' changes from learning to read to reading to learn. This transition is even more challenging in South Africa, where more than 70\% of the learners switch from an African language as LoLT in Grade 3 to English in Grade 4. To prepare students for this important switch, a sound development of English vocabulary in the Foundation Phase is essential for both English FAL and HL learners. Teachers have an important role to play to prepare their learners for these changing language demands. This small-scale exploratory study showed that Grade 3 teachers in South African schools that serve poor communities are capable of providing rich print exposure in their classrooms and that they expose their learners to a variety of basic vocabulary strategies. This suggests that schools can, to a certain extent, play a compensatory role for the limited literacy opportunities in homes of children from low SE backgrounds. However, the study also showed that some of the vocabulary teaching strategies employed were limited and did not reach an advanced level of active learning in which students were challenged and took ownership of their own vocabulary learning. In order for the learners to develop a more durable, rich vocabulary, their teachers would need to engage in more interactive and in-depth instruction.

Although the South African curriculum for grades 1-3 emphasises the importance of vocabulary development, the guidance that teachers are given through CAPS is limited. Future studies should investigate teachers' knowledge of vocabulary strategies at scale in order to inform national policy development. From the current study, it can be cautiously argued that teaching interactive and in-depth vocabulary instruction should be made a priority in teacher training programmes.

Finally, the fact that English FAL teachers relied almost solely on the use of the L1 for vocabulary instruction during English FAL lessons, even when learners were likely to understand the vocabulary in English, is noteworthy. It suggests that they may not know about different ways to build vocabulary in an FAL. This has implications for both pre-service and in-service teacher development programmes. Future research should investigate the L1-L2 vocabulary threshold for this particular English L2 Grade 3 level so that teaching methods could be adapted accordingly.

\section{Acknowledgements}

The author would like to extend her gratitude to the teachers for their generous participation in this study, as well as the Zenex Foundation for accommodating this study within the larger reading project, the Zenex Literacy Project (2015-2017), which was aimed at Foundation Phase teachers.

\section{Competing interests}

The author declares that she has no financial or personal relationships that may have inappropriately influenced her in writing this article.

\section{References}

Alderson, J.C., 1984, 'Reading in a foreign language: A reading problem or a language problem?', in J.C. Alderson \& A.H. Urquhart (eds.), Reading in a foreign language, pp. 1-24, Longman, London.

Anderson, N.J., 1999, Exploring second language reading: Issues and strategies, Heinle \& Heinle, Boston, MA.

Baumann, J., Blachowicz, C., Bates, A., Cieply, C., Manyak, P., Peterson, H., et al. (eds.), 2012, The development of a comprehensive vocabulary instruction program for nine- to eleven-year-old children using a design experiment approach, SLO, Enschede, The Netherlands.

Baumann, J.F., Edwards, E.C., Font, G., Tereshinski, C.A., Kame'enui, E.J. \& Olejnik, S., 2002, 'Teaching morphemic and contextual analysis to fifth-grade students', Reading Research Quarterly 37(2), 150-176. https://doi.org/10.1598/RRQ.37.2.3

Blachowicz, C.L.Z. \& Fisher, P.J., (eds.), 2015, Best practices in vocabulary instruction, Guilford Press, New York. 
Blachowicz, C.L.Z. \& Fisher, P.J.L. (eds.), 2000, Vocabulary instruction, vol. 3, Longman, New York.

Bryman, A., 2004, Social research methods, Oxford University Press, Oxford.

Cunningham, A., 2005, 'Chapter 3 vocabulary growth through independent reading and reading aloud to children', in E.H. Hiebert \& M.L. Kamil (eds.), Teaching and learning vocabulary, bringing research to practice, pp. 45-68, Lawrence Erlbaum, Mahwah, NJ.

Department of Basic Education, 2011, Curriculum and Assessment Policy Statement (CAPS) foundation phase grades 1-3, English first additional language, Department of Basic Education, Republic of South Africa, Pretoria.

Department of Basic Education, 2014, Second detailed indicator report for basic education sector, Department of Basic Education, Republic of South Africa, Pretoria.

Droop, M. \& Verhoeven, L., 2003, 'Language proficiency and reading ability in first and second language learners', Reading Research Quarterly 38(1), 78-103. https://doi. org/10.1598/RRQ.38.1.4

Egan, J. \& Pring, L., 2004, 'The processing of inflectional morphology: A comparison of children with and without dyslexia', Reading and Writing 17, 567-591. https:// doi.org/10.1023/B:READ.0000044433.30864.23

Ellis, N. \& Beaton, A., 1993, 'Psycholinguistic determinants of foreign language vocabulary learning', Language Learning 43, 559-617. https://doi.org/10.1111/ j.1467-1770.1993.tb00627.x

Fernald, A., Marchman, V.A. \& Weisleder, A., 2013, 'SES differences in language processing skill and vocabulary are evident at 18 months', Developmental Science 16(2), 234-248. https://doi.org/10.1111/desc.12019

Grabe, W., 2004, 'Research on teaching reading', Annual Review of Applied Linguistics 24, 44-69. https://doi.org/10.1017/S0267190504000030

Grabe, W., 2009, Reading in a second language: Moving from theory to practice, Cambridge University Press, New York, NY.

Hart, B. \& Risley, T., 1995, Meaningful differences in the everyday experience of young American children, Paul Brookes, Baltimore, MD.

Helman, L.A. \& Burns, M.K., 2008, 'What does oral language have to do with it? Helping young English-language learners acquire a sight word vocabulary', The Reading Teacher 62(1), 14-19. https://doi.org/10.1598/RT.62.1.2

Howie, S. \& Van Staden, S., 2012, South African children's reading literacy achievemen - PIRLS and prePIRLS 2011, Centre for Evaluation and Assessment, Pretoria.

Howie, S.J., Combrinck, C., Roux, K., Tshele, M., Mokoena, G.M. \& McLeod Palane, N., 2017, PIRLS literacy 2016 progress in international reading literacy study 2016 South African children's reading literacy achievement, Centre for Evaluation and Assessment, Pretoria.

Hoyt, L., 2002, Make it real: Strategies for success with informational text, Heinemann, Portsmouth, $\mathrm{NH}$.

Kuhn, M.R. \& Stahl, S.A., 1998, 'Teaching children to learn word meanings from context: A synthesis and some questions', Journal of Literacy Research 30(1), context: A synthesis and some questions', Journal of Liter
119-138. https://doi.org/10.1080/10862969809547983

Lems, K., Miller, L.D. \& Soro, T.M., 2017, Building literacy with English language learners, insights from linguistics, 2nd edn., The Guilford Press, New York.

MacDonald, C. \& Burroughs, E., 1991, Eager to talk and learn and think (Consolidated report of The Threshold Project), Maskew Miller Longman, Cape Town.

Mol, S.E. \& Bus, A.G., 2011, 'To read or not to read: A meta-analysis of print exposure from infancy to early adulthood', Psychological Bulletin 137(2), 267-296. https:// doi.org/10.1037/a0021890
Moloi, M.Q. \& Chetty, M., 2011, Trends in achievement levels of Grade 6 pupils in South Africa, Policy brief number 1, Southern and Eastern Africa Consortium for Monitoring Educational Quality (SACMEQ), Gaborone.

Mullis, I.V.S., Martin, M.O., Kennedy, A.M. \& Foy, P., 2007, PIRLS 2006 international report; IEA's progress in international reading literacy study in primary schools in 40 countries, International Association for the Evaluation of Educational Achievement (IEA), Boston, MA.

Nation, I.S.P., 2001, Learning vocabulary in another language, Cambridge University Press, New York.

Pretorius, E.J. \& Stoffelsma, L., 2017, 'How is their word knowledge growing? Exploring Grade 3 vocabulary in South African township schools', South African Journal of Early Childhood Development 7(1), 1-13. https://doi.org/10.4102/sajce.v7i1.553

Read, J., 2004, 'Research in teaching vocabulary', Annual Review of Applied Linguistics 24, 146-161. https://doi.org/10.1017/S0267190504000078

Ritchie, J. \& Lewis, J., 2012, Qualitative research practice. A guide for Social Science students and researchers, Sage Publications, London.

Ruddell, R.B. \& Shearer, B.A., 2002, “"Extraordinary," "tremendous," "exhilirating," "magnificent": Middle school at-risk students become avid word learners with the vocabulary self-collection strategy (VSS)', Journal of Adolescent and Adult Literacy 45, 352-363.

Schmitt, N., 2008, 'Instructed second language vocabulary learning', Language Teaching Research 12(3), 329-363. https://doi.org/10.1177/1362168808089921

Sibanda, J., 2014, Investigating the English vocabulary needs, exposure, and knowledge of IsiXhosa speaking learners for transition from learning to read in the foundation phase to reading to learn in the intermediate phase: A case study, Rhodes University, Grahamstown.

Spaull, N., 2011, A preliminary analysis of SACMEQ III South Africa, University of Stellenbosch, Stellenbosch.

Spaull, N., 2016, Learning to read and reading to learn, Department of Economics, University of Stellenbosch, Stellenbosch.

Spaull, N., 2017, Teaching reading for meaning: The Funda Wande project, viewed 08 February 2018, from http://www.allangrayorbis.org/entrepreneurship-blog/ cultivation/teaching-reading-meaning-funda-wande-project-dr-nic-spaull/

Stæhr, L.S., 2008, 'Vocabulary size and the skills of listening, reading and writing', Language Learning Journal 36(2), 139-152. https://doi.org/10.1080/09571730 802389975

Stahl, S.A., 2005, 'Four problems with teaching word meanings and what to do to make vocabulary an integral part of instruction', in E.H. Hiebert \& M.L. Kamil (eds.), Teaching and learning vocabulary: Bringing research to practice, Erlbaum, Mahwah, NJ.

Stoffelsma, L., 2019, 'English vocabulary exposure in South African township schools: Pitfalls and opportunities', Reading \& Writing, 10(1). https://doi.org/10.4102/ rw.v10i1.209

Tighe, E.L. \& Binder, K.S., 2015, 'An investigation of morphological awareness and processing in adults with low literacy', Applied Psycholinguistics 36, 245-273. https://doi.org/10.1017/S0142716413000222

Van der Berg, S., 2008, 'How effective are poor schools? Poverty and educational outcomes in South Africa', Studies in Educational Evaluation 34(3), 145-154. https://doi.org/10.1016/j.stueduc.2008.07.005

Wilsenach, C., 2015, 'Receptive vocabulary and early literacy skills in emergent bilingual Northern Sotho-English children', Reading \& Writing 6(1), 1-11. https:// doi.org/10.4102/rw.v6i1.77 